\title{
Relação da vegetação natural do Estado do Rio Grande do Sul com as disponibilidades climáticas
}

\author{
The relation between natural vegetation and climatic availability in Rio Grande do Sul state, \\ Brazil
}

\author{
Galileo Adeli Buriol', Valduino Estefanel ${ }^{\mathrm{II}}$, Álvaro Chagas de Chagas ${ }^{\mathrm{III}}$, Angélica Kuinchtner ${ }^{\mathrm{III}}$
}

\section{Resumo}

O clima do estado do Rio Grande do Sul (RS) é temperado úmido, condições de vegetação natural do tipo floresta temperada ou decidual, entretanto, em aproximadamente $46,3 \%$ de sua área, a vegetação é campestre. Assim, neste estudo, procurou-se colaborar no sentido de melhor entender as relações entre as condições climáticas e a vegetação natural do estado do RS. Para isso, relacionou-se a vegetação natural do estado do RS com as disponibilidades climáticas. Foram utilizados doze modelos fitoclimáticos e três classificações climáticas. Para o cálculo dos modelos e o enquadramento nas classificações climáticas, foram utilizadas as médias dos totais mensais e anuais da precipitação pluviométrica e evapotranspiração potencial, as médias, médias das máximas e médias das mínimas mensais e anuais das temperaturas do ar e as médias mensais e anuais das deficiências e excessos hídricos do solo de 41 estações meteorológicas, período 1931-1960 e, ainda, as médias mensais da radiação solar global de 25 estações meteorológicas, período 1957-1984. Pelos resultados obtidos para todas as estações meteorológicas utilizadas, as disponibilidades climáticas do estado são características de formação vegetal natural do tipo floresta. Dessa forma, tendo em vista que em torno de $46,3 \%$ da vegetação natural do estado é do tipo campestre, conclui-se que outros fatores, além do clima, interferem e/ou interferiram na formação da vegetação do Rio Grande do Sul.

Palavras-chave: Fitogeografia; Floresta; Campo; Clima

\begin{abstract}
The climate of the state of Rio Grande do Sul (RS) is humid temperate, conditions of natural vegetation of the kind called temperate or deciduous forest. However, in approximately $46.6 \%$ of its area the vegetation is country. Thus, in this study, we tried to corroborate in order to better understand the relationships between climatic conditions and the natural vegetation of RS state. To do so, the natural vegetation of RS was related to the climatic availability. Twelve phytoclimatic models and three climatic classifications were used. For the calculation of the models and the classification in the climatic classifications, the averages of the monthly and annual totals of the rainfall and potential evapotranspiration were used, the means, average of the maximum and average of the monthly and annual minimum of the air temperatures and the monthly averages and of the soil water deficiencies and excesses of 41 meteorological stations, period 1931-1960, and also the monthly averages of the global solar radiation of 25 meteorological stations, period 1957-1984. From the results obtained for all the meteorological stations used, the climatic availabilities of the state are characteristics of natural vegetation formation of the forest type. Thus, considering that about $46.3 \%$ of the state's natural vegetation is of the country type, it is concluded that other factors, in addition to the climate, interfere and/or have interfered in the formation of vegetation in Rio Grande do Sul state.
\end{abstract}

Keywords: Phytogeography; Forest; Field; Climate

\footnotetext{
I Engenheiro Agrônomo, Dr., Professor de Climatologia Ambiental do Curso de Engenharia Ambiental e Sanitária, Centro Universitário Franciscano, Rua Silva Jardim, 1323, Prédio 11, CEP 97010-491, Santa Maria (RS), Brasil. Bolsista do CNPq. galileo@unifa.br (ORCID 0000-0001-9713-3739).

II Engenheiro Agrônomo, Ms, Professor de Estatística do Curso de Engenharia Ambiental e Sanitária, Centro Universitário Franciscano, Rua Silva Jardim, 1323, Prédio 11, Conjunto II, CEP 97010-491, Santa Maria (RS), Brasil. (ORCID 0000-0001-5178-8182)

III Acadêmicos do Curso de Geografia do Centro Universitário Franciscano, Rua dos Andradas, 1614, Prédio 1, CEP 97010-32, Santa Maria (RS), Brasil. Bolsistas de Iniciação Científica. alv.ch@bol.com.br (Lattes 4121371313485441); akuinchtner@yahoo.com.br (ORCID 0000-0002-7600-3131).
} 


\section{Introdução}

Os principais fatores de formação dos diferentes tipos de vegetação são de origem climática e edáfica. Esses fatores agem simultaneamente, o clima determina o tipo de formação vegetal, e o solo, suas variações locais (RAMBO, 1956). Entretanto, autores como Veloso (1962), Miller (1966), Money (1974) e Marchiori $(2002 ; 2004)$ afirmam que o tipo de vegetação natural não se constitui, necessariamente, pela expressão do clima local e/ou regional, podendo ocorrer diferentes formações vegetais em regiões de características climáticas semelhantes, em função das diferenças edáficas, como capacidade de armazenamento de água e de condições de fertilidade.

No estado do Rio Grande do Sul (RS), as disponibilidades climáticas são favoráveis à formação de vegetação natural do tipo floresta subtropical e temperada. Contudo, em torno de $46,3 \%$ da vegetação natural é de campo. O mais contraditório é que, em uma mesma região, com características climáticas consideradas similares, existem áreas com florestas e com vegetação do tipo campestre, de forma intercalada. Segundo Rambo (1956), isso ocorre, principalmente, em função de restrições edáficas. Dessa forma, se o solo fosse apto para a vegetação do tipo floresta subtropical, essa formação ocuparia, ao menos, em um futuro remoto, toda a área do estado, pois, no caso da cobertura vegetal natural, as condições climáticas mantêm a primazia. Maack (1948), Klein (1975), Leite e Klein (1990), Marchiori (2002; 2004) e o próprio Rambo (1956) atribuem a existência, no estado do RS, de vegetação natural de florestas e campos, lado a lado, em regiões com disponibilidades climáticas, características físicas e químicas, inclusive, profundidade do solo e conformação geomorfológica semelhante, principalmente, à vigência de um clima anterior mais seco, semiárido.

A explicação da coexistência e alternância brusca de florestas e campos no estado do Rio Grande do Sul nas condições atuais de clima e solo, como função de um clima anterior seco, semiárido, segundo Marchiori (2004), "deve ser buscada na biologia das plantas representativas dos respectivos biomas e em suas vinculações com o relevo". De acordo com esse autor, nas regiões secas ou com solos arenosos, as gramíneas se adaptam melhor, em função de seu sistema radicular ser bastante ramificado, enquanto que em solos rochosos, nos quais a umidade se reparte de forma bastante irregular, as plantas lenhosas, por possuírem raízes de maior diâmetro e um sistema radicular mais extensivo, sobrevivem com mais eficiência. As gramíneas, em períodos sem deficiência hídrica no solo, crescem intensamente, mas têm um controle estomático ineficiente da transpiração durante o dessecamento do solo. Entretanto, o seu sistema radicular e seus tecidos meristemáticos, protegidos pela massa vegetal seca sobre o solo, não morrem e retomam o crescimento com o reumedecimento do solo. As plantas lenhosas, ao contrário das gramíneas, têm um eficiente controle estomático da transpiração em situação de deficiência hídrica. Quando o período de deficiência hídrica se prolonga, elas perdem as folhas, permanecendo vivos os ramos e as gemas. Mas, ao persistir a seca, e a deficiência de água no solo aumentando ainda mais, as reservas hídricas do lenho são esgotadas e as plantas morrem. Assim, essas diferenças podem explicar a existência dos campos no estado do RS como formações relituais em relação às florestas, no vigente clima ombrófilo.

É importante que sejam realizados novos estudos para tentar identificar prováveis explicações da relação da vegetação natural do estado com as disponibilidades climáticas. Isso pode ser realizado utilizando-se modelos fitoclimáticos e classificações climáticas, nos quais, respectivamente, os diferentes elementos climáticos e tipos climáticos são associados às distintas formações vegetais.

São poucos os estudos que relacionam à vegetação natural do estado ou da parte meridional da América do Sul com as disponibilidades climáticas. Aqueles de Burgos $(1969 ; 1970)$ e aquele de Buriol et al. (2007), provavelmente, sejam os únicos. Burgos $(1969 ; 1970)$ relacionou a distribuição geográfica da vegetação natural da Província de Buenos Aires e da Região Nordeste da Argentina com as disponibilidades climáticas, utilizando modelos fitoclimáticos e Buriol et al. (2007), a vegetação natural do estado do Rio Grande do Sul, utilizando o diagrama climático de Gaussen (1954), adaptado por Walter e Lieth (1960) ao estudo dos diferentes Zonobiomas da Terra (WALTER, 1986).

No presente estudo, objetivou-se determinar o ajuste da vegetação natural do estado do Rio Grande do Sul às disponibilidades climáticas regionais por meio de modelos fitoclimáticos e de classificações climáticas, o que permitirá aceitar ou rejeitar a hipótese de que a distribuição atual da vegetação não está condicionada ao clima vigente. 


\section{Material e métodos}

Foram utilizados modelos fitoclimáticos baseados na precipitação pluviométrica e temperatura do ar; na evapotranspiração potencial e em índices calculados a partir dos elementos do balanço hídrico climático; na precipitação pluviométrica, temperatura do ar e evapotranspiração potencial; no balanço de radiação; e nas classificações climáticas geradas a partir da precipitação pluviométrica e temperatura do ar, da evapotranspiração potencial e balanço hídrico do solo e do balanço hídrico do solo e temperatura do ar.

Os modelos fitoclimáticos baseados na precipitação pluviométrica e temperatura do ar foram: de Lang (1915) e Martonne (1926), Tabela 1, em que $\mathrm{I}_{\mathrm{L}}$ é o índice de Lang, $\mathrm{I}_{\mathrm{M}} \mathrm{o}$ índice de Martonne, P a precipitação pluviométrica média anual $(\mathrm{mm})$ e T a temperatura média anual $\left({ }^{\circ} \mathrm{C}\right)$; de Koeppen $(1931)$, Tabela 1, sendo $\mathrm{P}$ a precipitação pluviométrica média anual $(\mathrm{cm})$ e $\mathrm{T}$ a temperatura média anual $\left({ }^{\circ} \mathrm{C}\right)$; de Thornthwaite (1931), Tabela 1, em que (P-E) e (T-E) são, respectivamente, os índices de "eficácia da precipitação" e de "eficácia térmica", sendo P a precipitação pluviométrica média mensal (pol), T a temperatura média mensal $\left({ }^{\circ} \mathrm{F}\right)$ e E a evaporação média mensal $(\mathrm{mm})$, em que os valores de P-E e T-E são, respectivamente, as somas dos coeficientes dos 12 meses do ano; de Lauer (1952), Tabela 1, no qual as diferentes unidades fitogeográficas, em função do número de meses secos ou úmidos do ano, foram definidas utilizando-se a equação de Martonne (1926), em que P é a precipitação pluviométrica média mensal (cm) e $t$ a temperatura média mensal $\left({ }^{\circ} \mathrm{C}\right)$; de Gaussen (1954), pelo qual determinou-se o índice ombrotérmico por meio da representação, em um mesmo gráfico cartesiano, nas abscissas, os meses e, nas ordenadas, a precipitação pluviométrica $(\mathrm{mm})$ e a temperatura do ar $\left({ }^{\circ} \mathrm{C}\right)$, médias mensais, cada $1{ }^{\circ} \mathrm{C}$ correspondendo a $2 \mathrm{~mm}$, sendo que esse método foi adaptado para a representação das regiões homoclimáticas do mundo por Walter e Lieth (1960) e, para a distribuição geográfica dos diferentes Zonobiomas da Terra, por Walter (1986); de Miller (1966), no qual se construiu um gráfico cartesiano com a temperatura do ar $\left({ }^{\circ} \mathrm{F}\right)$, média anual (T), representada no eixo das abscissas e a precipitação pluviométrica (pol), média anual (P), no eixo das ordenadas, sendo, no ponto de origem, $32,0^{\circ} \mathrm{F}$ e 0,0 pol e as retas representadas pela Equação 1, limitando as condições climáticas de deserto daquelas de vegetação natural do tipo savana, estepe e mediterrânea, e pela Equação 2, as condições climáticas de vegetação natural do tipo savana, estepe e mediterrânea daquelas de selva; e de Whittaker (1975) e de Odum (1988) nos quais foram representados, de forma gráfica, respectivamente, os principais tipos de florestas naturais e os principais biomas da Terra em função da precipitação pluviométrica $(\mathrm{mm})$ e da temperatura do $\operatorname{ar}\left({ }^{\circ} \mathrm{C}\right)$, médias anuais.

Com base na evapotranspiração potencial e em índices calculados a partir dos elementos do balanço hídrico climático, foi utilizado o modelo de Thornthwaite e Hare (1955), Tabela 1, o qual é constituído dos Índices de Umidade (Im) e Eficiência Térmica (ET), em que "Ih" é o índice hídrico e "Ia" o índice de aridez, Tabela 1, respectivamente, Exc o excesso hídrico do solo, média anual (mm), Def a deficiência hídrica do solo, média anual $(\mathrm{mm})$ e ETP a evapotranspiração potencial, média anual $(\mathrm{mm})$ e o Índice de Eficiência Térmica (ET), igual à evapotranspiração potencial, média anual (mm).

Com base na precipitação pluviométrica, temperatura do ar e evapotranspiração potencial, foi utilizado o modelo de Holdridge (1978), o qual é constituído por um conjunto de hexágonos, cada um deles correspondendo a uma característica climática e, consequentemente, a um tipo de vegetação natural, no qual são plotados os dados de temperatura média anual do $\operatorname{ar}\left({ }^{\circ} \mathrm{C}\right)$, precipitação pluviométrica média anual $(\mathrm{mm})$ e da relação evapotranspiração potencial, média anual $(\mathrm{mm}) /$ precipitação pluviométrica, média anual $(\mathrm{mm})$.

Com base no balanço de radiação, utilizou-se o modelo de Budyko (1963), o qual é composto pelos índices hídrico e térmico, o primeiro determinado pela relação $\mathrm{Rn} / \mathrm{Lr}$, em que Rn é o balanço de radiação anual e $\mathrm{Lr}$ a energia consumida na evaporação da precipitação pluviométrica média anual e o segundo, expresso pelo próprio balanço anual de radiação (Rn), o qual, neste trabalho, foi estimado pela equação apresentada na Tabela 1, em que Rg é a irradiância solar global (BERGAMASCHI et al., 2003).

Procurou-se, no caso presente, utilizar modelos fitoclimáticos de alcance universal, embora a maior parte deles publicados há muitos anos e não aqueles gerados para estudo da vegetação de uma região ou país específico como o de Yanling et al. (2008), para a China ou, ainda, gerados a partir de modelos já existentes, como o de Tchebakova et al. (1993), com base naquele de Budyko (1963).

As classificações climáticas utilizadas foram a de Koeppen (1948), de Thornthwaite (1948) e de Camargo (1991). Essas classificações são baseadas, respectivamente, na precipitação pluviométrica $(\mathrm{cm})$ e temperatura do ar $\left({ }^{\circ} \mathrm{C}\right)$; na evapotranspiração potencial $(\mathrm{mm})$ e elementos do balanço hídrico do solo 
(mm); e na temperatura do $\operatorname{ar}\left({ }^{\circ} \mathrm{C}\right)$ e elementos do balanço hídrico do solo. Para as classificações climáticas de Koeppen (1948) e de Thornthwaite (1948), utilizaram-se as cartas climáticas do estado do Rio Grande do Sul realizadas por Kuinchtner e Buriol (2001) e, para a classificação de Camargo (1991), os parâmetros térmicos temperatura média anual e média do mês mais frio e os excessos e deficiências hídricas, médias anuais.

Os dados de temperatura do ar e de precipitação pluviométrica utilizados nos modelos fitoclimáticos e nas classificações climáticas foram coletados de 41 estações meteorológicas pertencentes ao $8^{\circ}$ Distrito de Meteorologia ( $8^{\circ}$ DISME) e publicados em Instituto de Pesquisas Agronômicas (1989), período de registro 1931-1960. Foram utilizados os valores normais do período 1931-1960 em razão de que aqueles do período 1961-1990 foram de um número menor de estações. Os dados de radiação solar global também foram coletados em Instituto de Pesquisas Agronômicas (1989), período de observação 1957-1984, de 25 estações meteorológicas pertencentes à Fundação Estadual de Pesquisa Agropecuária - FEPAGRO. $\mathrm{Na}$ Tabela 2, estão relacionadas as coordenadas geográficas das estações meteorológicas utilizadas. Os parâmetros hídricos foram obtidos a partir do cálculo da evapotranspiração potencial e do balanço hídrico segundo Thornthwaite (1948) e Thornthwaite e Mather (1955), respectivamente, considerando o armazenamento de água disponível no solo igual a $100 \mathrm{~mm}$.

Tabela 1 -Modelos fitoclimáticos utilizados para relacionar a vegetação natural do estado do Rio Grande do Sul com as disponibilidades climáticas.

Table 1- Phytoclimate models used to relate the state natural vegetation with climate availabilities.

\begin{tabular}{|c|c|c|c|}
\hline Modelo & Equação & Modelo & Equação \\
\hline Lang (1915) & $I=\frac{P}{T}$ & $\begin{array}{l}\text { Miller (1966) } \\
\text { (Equação 1) }\end{array}$ & $P=\frac{T}{5}$ \\
\hline $\begin{array}{l}\text { Martonne } \\
\text { (1926) }\end{array}$ & $I=\frac{P}{(T+10)}$ & $\begin{array}{l}\text { Miller (1966) } \\
\text { (Equação 2) }\end{array}$ & $P=\left(3 \frac{T}{4}\right)-12$ \\
\hline Koeppen (1931) & $P=2 T+14$ & $\begin{array}{c}\text { Thornthwaite e } \\
\text { Hare (1955) }\end{array}$ & $\operatorname{Im}=I h-0,6 l a$ \\
\hline $\begin{array}{l}\text { Thornthwaite } \\
\text { (1931) }\end{array}$ & $(P-E)=\frac{(11,5 P)}{(T-10)^{\left(\frac{9}{10}\right)}}$ & Índice hídrico & $I h=100 \cdot\left(\frac{(E x c)}{(E T P)}\right)$ \\
\hline $\begin{array}{l}\text { Thornthwaite } \\
\text { (1931) }\end{array}$ & $(T-E)=\frac{(T-32)}{4}$ & Índice de aridez & $I a=100 \cdot\left(\frac{(D e f)}{(E T P)}\right)$ \\
\hline Lauer (1952) & $P=2 t+10$ & $\begin{array}{l}\text { Bergamaschi } e t \\
\text { al. (2003) }\end{array}$ & $R n=-18,81+0,69 R g$ \\
\hline
\end{tabular}

\section{Resultados e discussão}

Os resultados obtidos com os modelos fitoclimáticos baseados na precipitação pluviométrica e temperatura do ar estão representados nas Figuras 1a a 1f, 2a e 2b. Pelo modelo de Lang (1915), Figura 1a, as estações meteorológicas em que ocorrem precipitações pluviométricas elevadas, como São Francisco de Paula, Caxias, Bom Jesus, Palmeira das Missões e Soledade, se enquadram na zona 
úmida de bosque denso e, nas outras estações, as características são de clima úmido de bosque ralo; pelo modelo de Martonne (1926), Figura 1b, a maior parte das estações se enquadra na zona climática úmida e aquelas cujas precipitações são mais elevadas, na zona hiperúmida; pelo modelo de Koeppen (1931), Figura 1c, todas as estações se enquadram nas condições climáticas de vegetação de bosque; pelo modelo de Thornthwaite (1931), Figura 1d, com exceção das estações de São Francisco de Paula e de Soledade, que se situam na zona de selva, todas as outras se enquadram na zona de bosque; pelo modelo de Lauer (1952), em nenhuma das 41 estações utilizadas ocorrem meses secos e, assim, considerando os valores das temperaturas médias mensais destas estações, conclui-se que as disponibilidades climáticas no estado são características de vegetação do tipo floresta temperada e subtropical; pelo modelo de Gaussen (1954), considerando-o como foi utilizado por Walther e Lieth (1960), para a representação geográfica dos diferentes Zonobiomas da Terra (WALTER, 1986), as estações se enquadram em clima temperado quente e úmido, sendo característico de vegetação natural do tipo floresta, como se observa na Figura 1e, utilizando quatro estações meteorológicas, respectivamente, com valores baixos (Santa Vitória do Palmar), médios (Itaqui), altos (Santa Maria) e muito altos (São Francisco de Paula) de precipitação pluviométrica; pelo modelo de Miller (1966), Figura 1f, em todas as estações, a vegetação natural é do tipo selva; pelo modelo de Whittaker (1975), Figura 2a, as estações localizadas na parte mais continental do estado, com temperatura média anual acima de $19,6^{\circ} \mathrm{C}$ como Itaqui, São Borja, São Luiz Gonzaga, Uruguaiana, se enquadram em condições de clima de floresta sazonal tropical, naquelas situadas na Região do Litoral Sul, como Santa Vitória do Palmar, Rio Grande e Tapes, com precipitação pluviométrica média anual em torno de $1200 \mathrm{~mm}$, a vegetação natural é de bosque de área úmida ou de vegetação arbustiva e, na maior parte das estações, as condições climáticas são de floresta de clima temperado; e, pelo modelo de National Science Foundation (ODUM, 1988), Figura 2b, com exceção de São Francisco de Paula, em todos as outras estações, é de um bioma do tipo floresta decidual.

\section{Figura 1 - Distribuição das estações meteorológicas do estado do Rio Grande do Sul nos modelos fitoclimáticos de Lang (a), Martonne (b), Koeppen (c) e Thornthwaite (d), no diagrama climático de Gaussen (e) (somente as estações meteorológicas de Santa Vitória do Palmar, Itaqui, Santa Maria e São Francisco de Paula) e no modelo fitoclimático de Miller (f).}

Figure 1 - Meteorological stations distribution in Rio Grande do Sul state according to phytoclimatic models of Lang (a), Martonne (b), Koeppen (c) and Thornthwaite (d), in the Gaussen climatic diagram (e) (only the Santa Vitória do Palmar, Itaqui, Santa Maria and São Francisco de Paula meteorological stations) and Miller's phytoclimatic model (f).
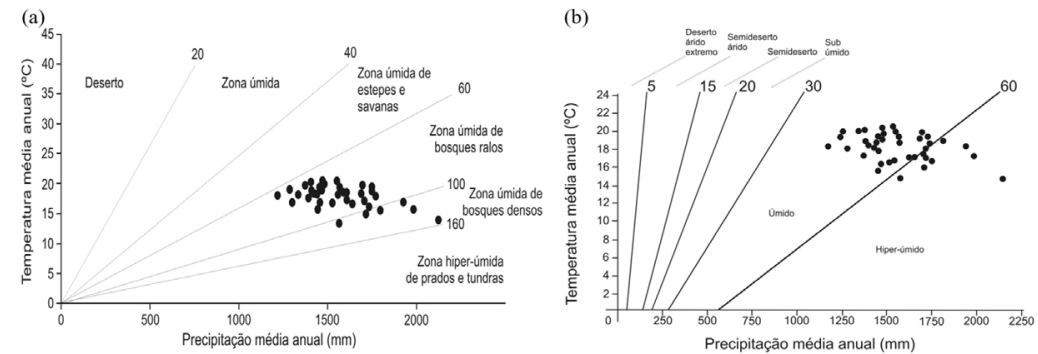

(c)

(d)
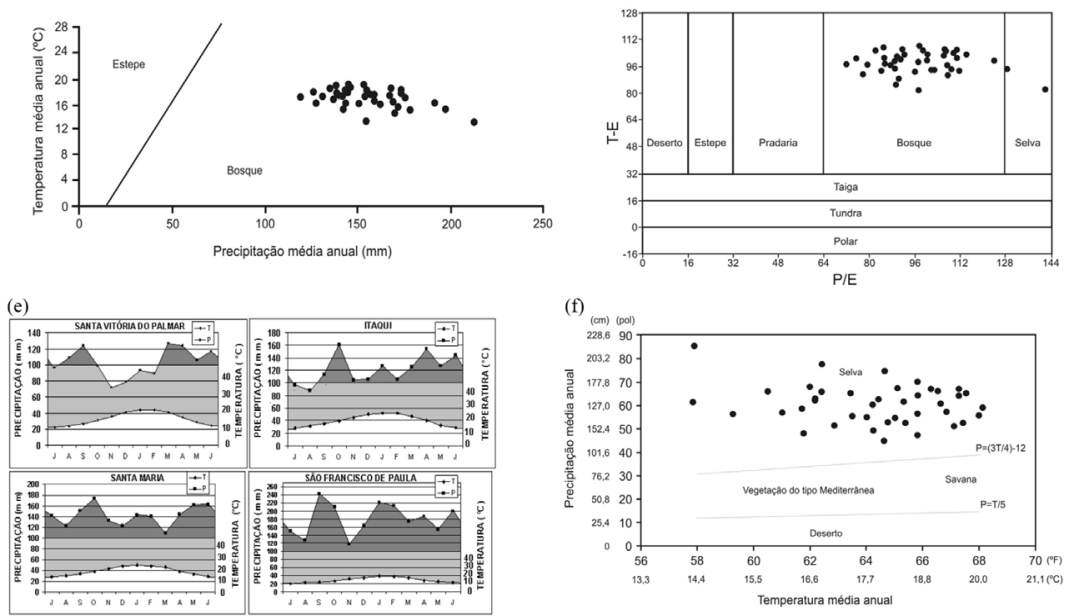
Tabela 2 - Coordenadas geográficas das estações meteorológicas do estado do Rio Grande do Sul utilizadas, 41 pertencentes ao $8^{\circ}$ Distrito de Meteorologia $-8^{\circ}$ DISME do Instituto Nacional de Meteorologia - INMET e 25 pertencentes à Fundação Estadual de Pesquisa Agropecuária FEPAGRO.

Table 2 - Correlation and geographic coordinates of Rio Grande do Sul state's meteorological stations, belonging to the 8th District of Meteorology (8th DISME), used in phytoclimate and climate classifications models and those belonging to FEPAGRO whose global solar radiation data were used in Budyko (1963) phytoclimate model calculations.

\begin{tabular}{|c|c|c|c|c|c|c|c|}
\hline Estação & Latitude(S) & Longitude (W) & Altitude (m) & Estação & Latitude (S) & Longitude (W) & $\begin{array}{c}\text { Altitude } \\
\text { (m) }\end{array}$ \\
\hline \multicolumn{4}{|c|}{ Estações do $8^{\circ}$ DISME } & $\begin{array}{c}\text { Santana } \\
\text { Livramento }\end{array}$ & $30^{\circ} 53^{\prime} 18^{\prime \prime}$ & $55^{\circ} 31^{\prime} 56^{\prime \prime}$ & 210 \\
\hline Iraí & $27^{\circ} 11^{\prime} 45^{\prime \prime}$ & $53^{\circ} 14^{\prime} 01^{\prime \prime}$ & 227 & Dom Pedrito & $30^{\circ} 58^{\prime} 57^{\prime \prime}$ & $54^{\circ} 39^{\prime} 56^{\prime \prime}$ & 140 \\
\hline Marcelino Ramos & $27^{\circ} 27^{\prime} 40^{\prime \prime}$ & $51^{\circ} 54^{\prime} 22^{\prime \prime}$ & 383 & Bagé & $31^{\circ} 20^{\prime} 13^{\prime \prime}$ & $54^{\circ} 06^{\prime} 21^{\prime \prime}$ & 216 \\
\hline Santa Rosa & $27^{\circ} 51^{\prime} 50^{\prime \prime}$ & $54^{\circ} 25^{\prime} 59^{\prime \prime}$ & 360 & Piratini & $31^{\circ} 26^{\prime} 54^{\prime \prime}$ & $53^{\circ} 06^{\prime} 09^{\prime \prime}$ & 345 \\
\hline $\begin{array}{l}\text { Palmeira das } \\
\text { Missões }\end{array}$ & $27^{\circ} 53^{\prime} 55$ & $53^{\circ} 26^{\prime} 45^{\prime \prime}$ & 634 & Pelotas & $31^{\circ} 45^{\prime} 00^{\prime \prime}$ & $52^{\circ} 21^{\prime} 00^{\prime \prime}$ & 7 \\
\hline Passo Fundo & $28^{\circ} 15^{\prime} 39^{\prime \prime}$ & $52^{\circ} 24^{\prime} 33^{\prime \prime}$ & 678 & Rio Grande & $32^{\circ} 01^{\prime} 44^{\prime \prime}$ & $52^{\circ} 05^{\prime} 40^{\prime \prime}$ & 8 \\
\hline Santo Ângelo & $28^{\circ} 18^{\prime} 14^{\prime \prime}$ & $54^{\circ} 15^{\prime} 52^{\prime \prime}$ & 289 & Jaguarão & $32^{\circ} 33^{\prime} 32^{\prime \prime}$ & $53^{\circ} 23^{\prime} 20^{\prime \prime}$ & 11 \\
\hline São Luiz Gonzaga & $28^{\circ} 23^{\prime} 53^{\prime \prime}$ & $54^{\circ} 58^{\prime} 18^{\prime \prime}$ & 254 & $\begin{array}{c}\text { Sta Vitória do } \\
\text { Palmar }\end{array}$ & $33^{\circ} 31^{\prime} 14^{\prime \prime}$ & $53^{\circ} 21^{\prime} 47^{\prime \prime}$ & 6 \\
\hline Lagoa Vermelha & $28^{\circ} 25^{\prime} 35^{\prime \prime}$ & $51^{\circ} 35^{\prime} 51^{\prime \prime}$ & 805 & \multicolumn{4}{|c|}{ Estações da FEPAGRO } \\
\hline Vacaria & $28^{\circ} 33^{\prime} 00^{\prime \prime}$ & $50^{\circ} 42^{\prime} 21^{\prime \prime}$ & 955 & Erexim & $27^{\circ} 37^{\prime} 45^{\prime \prime}$ & $52^{\circ} 16^{\prime} 33^{\prime \prime}$ & 760 \\
\hline Cruz Alta & $28^{\circ} 38^{\prime} 21^{\prime \prime}$ & $53^{\circ} 36^{\prime} 34^{\prime \prime}$ & 473 & Santo Augusto & $27^{\circ} 54^{\prime} 16^{\prime \prime}$ & $53^{\circ} 45^{\prime} 14^{\prime \prime}$ & 380 \\
\hline São Borja & $28^{\circ} 39^{\prime} 44^{\prime \prime}$ & $56^{\circ} 00^{\prime} 15^{\prime \prime}$ & 73 & Passo Fundo & $28^{\circ} 15^{\prime} 41^{\prime \prime}$ & $52^{\circ} 24^{\prime} 45^{\prime \prime}$ & 709 \\
\hline Bom Jesus & $28^{\circ} 40^{\prime} 10^{\prime \prime}$ & $50^{\circ} 26^{\prime} 25^{\prime \prime}$ & 1047 & Ijuí & $28^{\circ} 23^{\prime} 17^{\prime \prime}$ & $53^{\circ} 54^{\prime} 50^{\prime \prime}$ & 448 \\
\hline Guaporé & $28^{\circ} 55^{\prime} 44^{\prime \prime}$ & $51^{\circ} 54^{\prime} 45^{\prime \prime}$ & 450 & Vacaria & $28^{\circ} 30^{\prime} 09^{\prime \prime}$ & $50^{\circ} 56^{\prime} 12^{\prime \prime}$ & 955 \\
\hline Soledade & $29^{\circ} 03^{\prime} 14^{\prime \prime}$ & $52^{\circ} 26^{\prime} 00^{\prime \prime}$ & 720 & Cruz Alta & $28^{\circ} 38^{\prime} 21$ & $53^{\circ} 36^{\prime} 34$ & 473 \\
\hline Itaqui & $29^{\circ} 07^{\prime} 10^{\prime \prime}$ & $56^{\circ} 32^{\prime} 52^{\prime \prime}$ & 53 & São Borja & $28^{\circ} 39^{\prime} 44^{\prime \prime}$ & $56^{\circ} 00^{\prime} 44^{\prime \prime}$ & 99 \\
\hline Bento Gonçalves & $29^{\circ} 10^{\prime} 00^{\prime \prime}$ & $51^{\circ} 25^{\prime} 00^{\prime \prime}$ & 619 & $\begin{array}{l}\text { Júlio de } \\
\text { Castilhos }\end{array}$ & $29^{\circ} 13^{\prime} 26^{\prime \prime}$ & $53^{\circ} 40^{\prime} 45^{\prime \prime}$ & 514 \\
\hline Caxias do Sul & $29^{\circ} 10^{\prime} 25^{\prime \prime}$ & $51^{\circ} 12^{\prime} 21^{\prime \prime}$ & 740 & Veranópolis & $28^{\circ} 56^{\prime} 14^{\prime \prime}$ & $51^{\circ} 33^{\prime} 11^{\prime \prime}$ & 705 \\
\hline Santiago & $29^{\circ} 11^{\prime} 00^{\prime \prime}$ & $54^{\circ} 53^{\prime} 10^{\prime \prime}$ & 426 & Alegrete & $29^{\circ} 46^{\prime} 59^{\prime \prime}$ & $55^{\circ} 46^{\prime} 59$ & 96 \\
\hline Júlio de Castilhos & $29^{\circ} 13^{\prime} 26^{\prime \prime}$ & $53^{\circ} 40^{\prime} 45^{\prime \prime}$ & 516 & Farroupilha & $29^{\circ} 14^{\prime} 30^{\prime \prime}$ & $51^{\circ} 26^{\prime} 20^{\prime \prime}$ & 702 \\
\hline $\begin{array}{l}\text { São Francisco de } \\
\text { Paula }\end{array}$ & $29^{\circ} 20^{\prime} 00^{\prime \prime}$ & $50^{\circ} 31^{\prime} 21^{\prime \prime}$ & 912 & Osório & $29^{\circ} 40^{\prime} 49^{\prime \prime}$ & $50^{\circ} 13^{\prime} 56^{\prime \prime}$ & 32 \\
\hline Torres & $29^{\circ} 20^{\prime} 34^{\prime \prime}$ & $49^{\circ} 43^{\prime} 39^{\prime \prime}$ & 43 & Santa Maria & $29^{\circ} 41^{\prime} 24^{\prime \prime}$ & $53^{\circ} 48^{\prime} 42^{\prime \prime}$ & 153 \\
\hline Santa Maria & $29^{\circ} 41^{\prime} 25^{\prime \prime}$ & $53^{\circ} 48^{\prime} 42^{\prime \prime}$ & 138 & Uruguaiana & $29^{\circ} 45^{\prime} 23^{\prime \prime}$ & $57^{\circ} 05^{\prime} 37^{\prime \prime}$ & 74 \\
\hline Uruguaiana & $29^{\circ} 45^{\prime} 23^{\prime \prime}$ & $57^{\circ} 05^{\prime} 12^{\prime \prime}$ & 69 & Taquari & $29^{\circ} 48^{\prime} 15^{\prime \prime}$ & $51^{\circ} 49^{\prime} 30^{\prime \prime}$ & 76 \\
\hline Santa Cruz do Sul & $29^{\circ} 43^{\prime} 05^{\prime \prime}$ & $52^{\circ} 25^{\prime} 45^{\prime \prime}$ & 56 & Tramandaí & $29^{\circ} 56^{\prime} 22^{\prime \prime}$ & $50^{\circ} 30^{\prime} 12^{\prime \prime}$ & 3 \\
\hline Taquara & $29^{\circ} 45^{\prime} 00^{\prime \prime}$ & $50^{\circ} 45^{\prime} 00^{\prime \prime}$ & 29 & Cachoeirinha & $29^{\circ} 57^{\prime} 36$ & $51^{\circ} 04^{\prime} 22$ & 4 \\
\hline Alegrete & $29^{\circ} 46^{\prime} 47^{\prime \prime}$ & $55^{\circ} 47^{\prime} 15^{\prime \prime}$ & 116 & Guaíba & $30^{\circ} 05^{\prime} 52^{\prime \prime}$ & $51^{\circ} 39^{\prime} 08^{\prime \prime}$ & 46 \\
\hline Taquari & $29^{\circ} 48^{\prime} 15^{\prime \prime}$ & $51^{\circ} 49^{\prime} 30^{\prime \prime}$ & 76 & São Gabriel & $30^{\circ} 20^{\prime} 27^{\prime \prime}$ & $54^{\circ} 19^{\prime} 01^{\prime \prime}$ & 109 \\
\hline Porto Alegre & $30^{\circ} 01^{\prime} 53^{\prime \prime}$ & $51^{\circ} 01^{\prime} 53^{\prime \prime}$ & 10 & Quaraí & $30^{\circ} 23^{\prime} 17^{\prime \prime}$ & $56^{\circ} 26^{\prime} 53^{\prime \prime}$ & 100 \\
\hline Cachoeira do Sul & $30^{\circ} 02^{\prime} 45^{\prime \prime}$ & $52^{\circ} 53^{\prime} 39^{\prime \prime}$ & 72 & $\begin{array}{c}\text { Encruzilhada } \\
\text { do Sul }\end{array}$ & $30^{\circ} 32^{\prime} 35^{\prime \prime}$ & $52^{\circ} 31^{\prime} 20^{\prime \prime}$ & 420 \\
\hline
\end{tabular}

Continuação... 
Tabela 2 - Continuação...

Table 2 - Continuend...

\begin{tabular}{|c|c|c|c|c|c|c|c|}
\hline Estação & Latitude(S) & $\begin{array}{l}\text { Longitude } \\
\text { (W) }\end{array}$ & $\begin{array}{l}\text { Altitude } \\
\text { (m) }\end{array}$ & Estação & $\begin{array}{l}\text { Latitude } \\
\text { (S) }\end{array}$ & $\begin{array}{l}\text { Longitude } \\
\text { (W) }\end{array}$ & $\begin{array}{l}\text { Altitude } \\
\text { (m) }\end{array}$ \\
\hline São Gabriel & $30^{\circ} 20^{\prime} 27^{\prime \prime}$ & $54^{\circ} 19^{\prime} 01^{\prime \prime}$ & 124 & $\begin{array}{l}\text { Santana do } \\
\text { Livramento }\end{array}$ & $30^{\circ} 53^{\prime} 18^{\prime \prime}$ & $55^{\circ} 31^{\prime} 56^{\prime \prime}$ & 210 \\
\hline Caçapava do Sul & $30^{\circ} 30^{\prime} 32^{\prime \prime}$ & $53^{\circ} 29^{\prime} 22^{\prime \prime}$ & 450 & Bagé & $31^{\circ} 20^{\prime} 14^{\prime \prime}$ & $54^{\circ} 05^{\prime} 59^{\prime \prime}$ & 214 \\
\hline $\begin{array}{l}\text { Encruzilhada do } \\
\text { Sul }\end{array}$ & $30^{\circ} 32^{\prime} 35^{\prime \prime}$ & $52^{\circ} 31^{\prime} 20^{\prime \prime}$ & 420 & Rio Grande & $32^{\circ} 01^{\prime} 02^{\prime \prime}$ & $52^{\circ} 09^{\prime} 32^{\prime \prime}$ & 16 \\
\hline Tapes & $30^{\circ} 50^{\prime} 00^{\prime \prime}$ & $30^{\circ} 50^{\prime} 00^{\prime \prime}$ & 5 & Jaguarão & $32^{\circ} 33^{\prime} 32^{\prime \prime}$ & $53^{\circ} 23^{\prime} 20^{\prime \prime}$ & 11 \\
\hline
\end{tabular}

Figura 2 - Distribuição das estações meteorológicas do estado do Rio Grande do Sul nos modelos fitoclimáticos de Whittaker (a), Odun (b), Thornthwaite e Hare (c), Holdrige (d) e Budyko (e) e distribuição geográfica dos tipos climáticos do Estado segundo a classificação de Koeppen (f).

Figure 2 - Meteorological stations distribution in Rio Grande do Sul state according to phytoclimatic models of Whittaker (a), Odun (b), Thornthwaite \& Hare (c), Holdrige (d) and Budyko (e) and geographic distribution of the types of climatic conditions in the state as classified by Koeppen (f).

a)

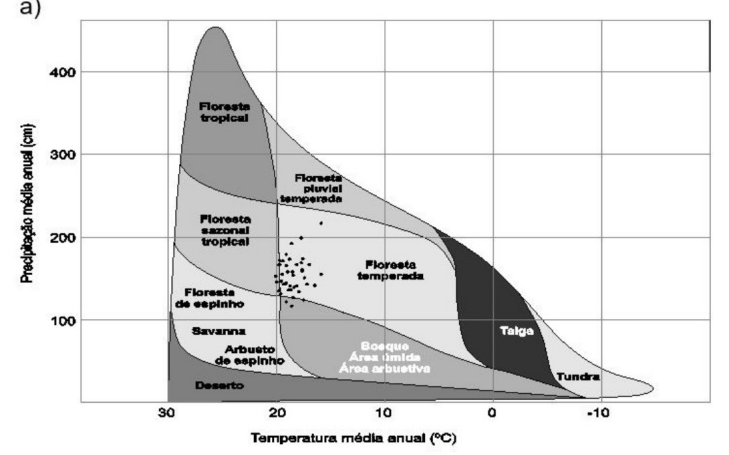

c)

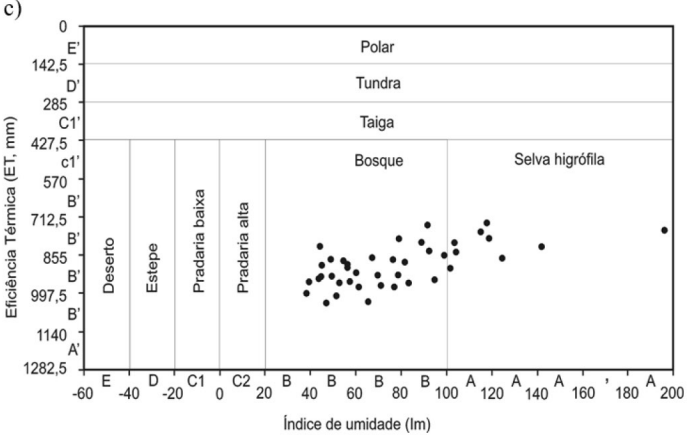

e)

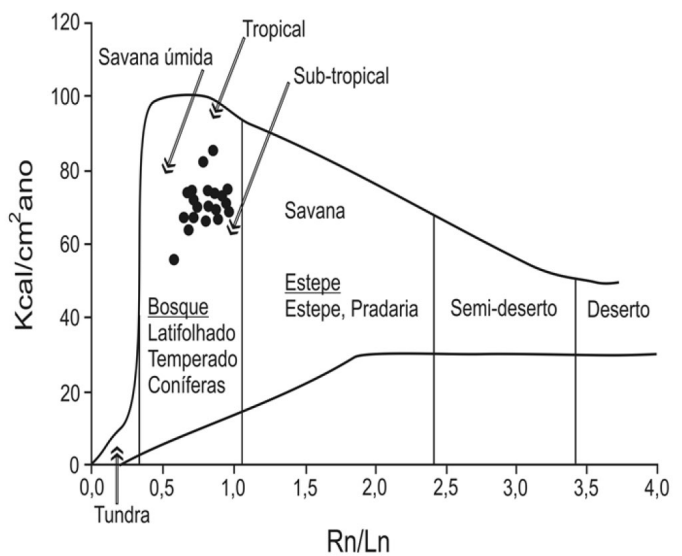

b)

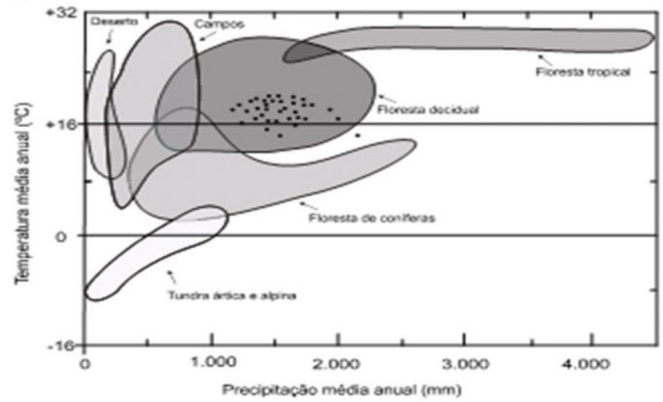

d)

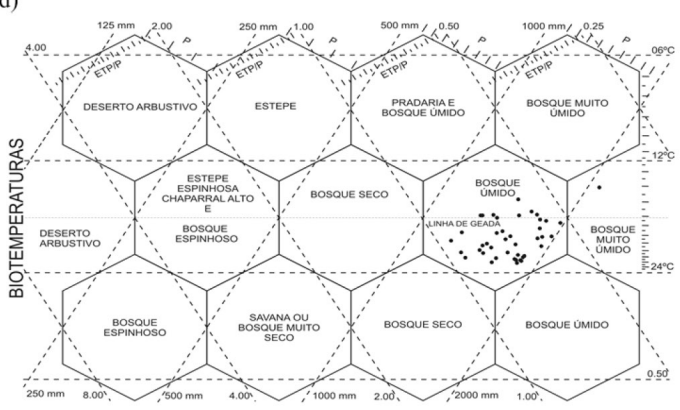

f)

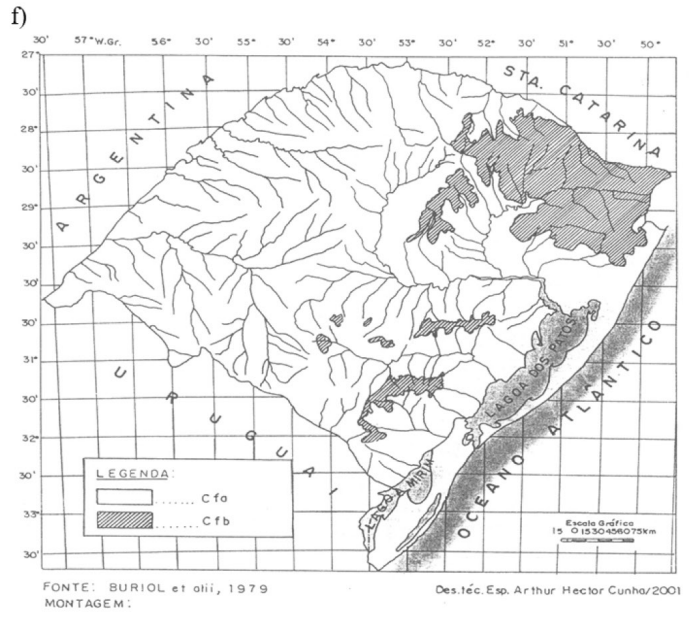


Com base na precipitação pluviométrica, temperatura do ar e evapotranspiração potencial, modelo de Thornthwaite e Hare (1955), as condições climáticas na maioria das estações meteorológicas são de vegetação natural do tipo bosque e, com mais chuva no estado, como em São Francisco de Paula, Soledade e Palmeira das Missões, de selva higrófila (Figura 2c).

Com base nos elementos climáticos precipitação pluviométrica, temperatura do ar e evapotranspiração potencial (HOLDRIDGE, 1978), Figura 2d, a maioria das estações meteorológicas situa-se no polígono correspondente às condições climáticas de vegetação do tipo bosque úmido, sendo que algumas estações, como Palmeira das Missões, São Francisco de Paula e Soledade, localizam-se no polígono correspondente ao clima de vegetação tipo bosque muito úmido.

Com base no balanço de radiação e evaporação (BUDYKO, 1963), Figura 2e, em todas as estações, a vegetação natural é do tipo subtropical.

Pela classificação climática de Koeppen (1948), Figura 2f, o clima do estado é do tipo Cf, temperado úmido sem estação seca, com temperatura média do mês mais quente inferior a $22,0^{\circ} \mathrm{C}(\mathrm{Cfb})$ nas regiões climáticas da Serra do Nordeste e nas partes de maior altitude do Planalto e da Serra do Sudeste e com temperatura média do mês mais quente superior a $22,0^{\circ} \mathrm{C}(\mathrm{Cfa})$ no restante do estado, caracterizando condições de vegetação natural, respectivamente, do tipo floresta de clima temperado e subtropical.

Figura 3 - Distribuição geográfica dos tipos climáticos do estado do Rio Grande do Sul segundo o

Índice de Eficiência Hídrica (a) e Índice de Eficiência Térmica de Thornthwaite (b), classificação climática das estações meteorológicas do Rio Grande do Sul em função do fator térmico (c) e hídrico

(d) de Camargo.

Figure 3 - Climatic types geographic distribution in Rio Grande do Sul state according to the Water Efficiency Index (a) and Thermal Efficiency Index of Thornthwaite (b), climatic classification of the meteorological stations of Rio Grande do Sul because of the thermal factor (c) and water (d) of Camargo.

a)
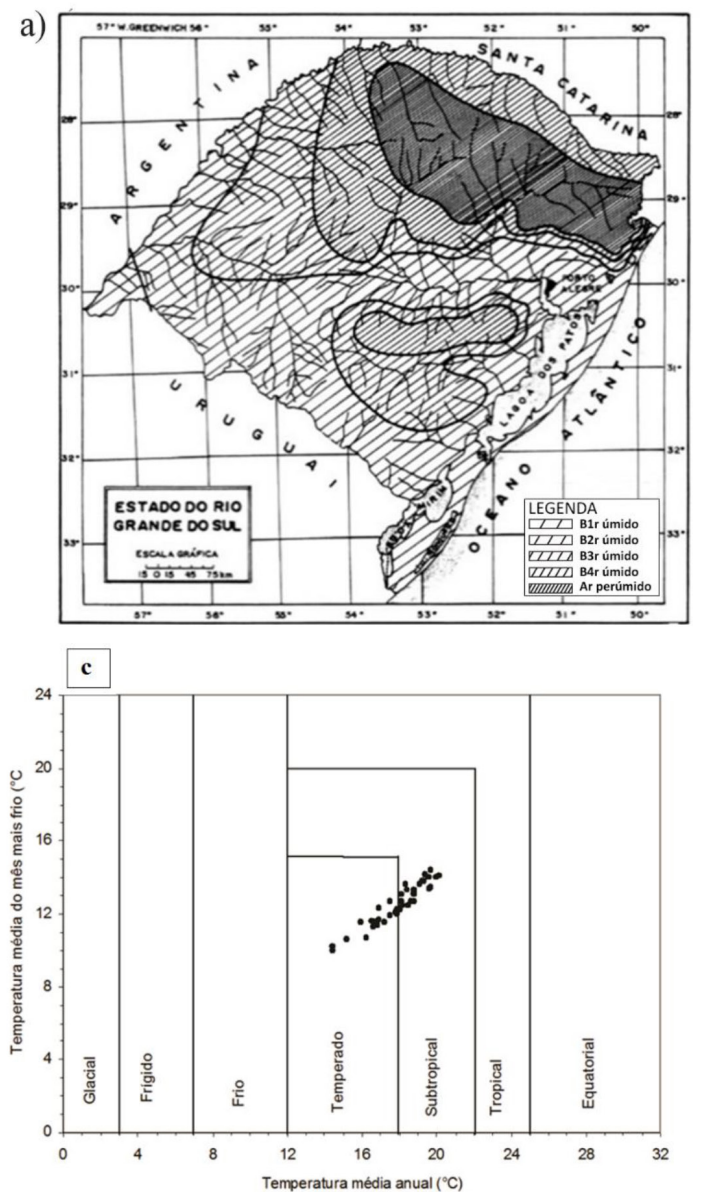

b)
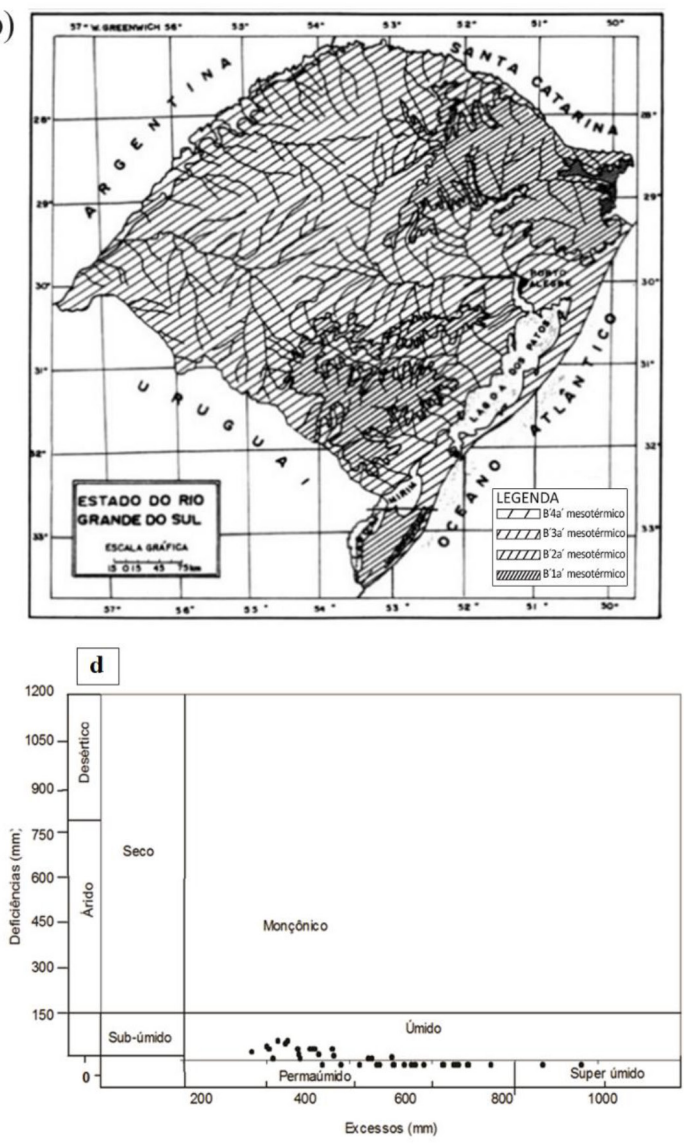
Pela classificação de Thornthwaite (1948), os valores do índice Efetivo de Umidade (Im), Figura 3a, variam de 38, em Uruguaiana, a 195, em São Francisco de Paula, sendo o clima do estado do tipo superúmido (Ar) e úmido (B4r, B3r, B2r e B1r), com pouca ou nenhuma deficiência hídrica anual e os valores do índice de Eficiência Térmica (ET), Figura 3b, variam de em torno de 700 a 1000, respectivamente, nas regiões mais frias e mais quentes do estado, sendo o clima do tipo mesotérmico, com o percentual de evapotranspiração potencial anual concentrada no verão menor do que $48 \%\left(\mathrm{~B}^{\prime} 4 \mathrm{a}^{\prime}, \mathrm{B}^{\prime} 3 \mathrm{a}^{\prime}, \mathrm{B}^{\prime} 2 \mathrm{a}^{\prime} \mathrm{e}\right.$ $\left.\mathrm{B}^{\prime} 1 \mathrm{a}^{\prime}\right)$, sendo estas condições climáticas características de vegetação natural do tipo floresta higrófila. Pela classificação de Camargo (1991), Figuras 3c e 3d, as condições térmicas, nas regiões climáticas do Litoral Norte, Depressão Central, Missões, Alto e Baixo Vale do Uruguai e parte oeste da Campanha são de clima subtropical e nas Regiões da Serra do Nordeste, Planalto, Serra do Sudeste, Litoral Sul e parte leste da Campanha, temperado e as condições hídricas do solo na Serra do Nordeste e Planalto são de clima do tipo superúmido, nas Missões, Alto Vale do Uruguai, Depressão Central, Serra do Sudeste e Litoral Norte, do tipo perúmido e no Litoral Sul, Campanha e Baixo Vale do Uruguai, do tipo úmido, sendo, assim, tanto as características térmicas como as hídricas, de vegetação natural do tipo floresta.

Pelos resultados obtidos, tanto por meio dos modelos fitoclimáticos como pelas classificações climáticas, as disponibilidades climáticas do estado do Rio Grande do Sul caracterizam-se como de vegetação do tipo floresta. Assim, infere-se que não é suficiente a expressão geral do clima para definir a distribuição geográfica da vegetação natural do estado: existem, além das condições climáticas atuais, outros fatores que condicionam ou condicionaram a formação vegetal natural do estado. Dessa forma, é muito importante intensificar os estudos para identificar esses fatores, principalmente, na relação da vegetação natural com as características dos principais tipos de solos e com as condições climáticas do passado. Segundo Burgos (1970), o "ajuste de normas fitoclimáticas e edafoclimáticas ao clima atual tem apenas um alcance limitado, pois a vegetação atual e, especialmente, os solos são resultados da ação do clima atual sobre o efeito do clima de épocas passadas".

\section{Conclusões}

Pelos resultados obtidos por meio dos modelos fitoclimáticos e das classificações climáticas, as disponibilidades climáticas em todo o território do estado do Rio Grande do Sul são de vegetação natural do tipo floresta.

A vegetação natural atual do tipo campestre do estado do Rio Grande do Sul não é explicada em função das disponibilidades climáticas ocorrentes.

\section{Referências}

BERGAMASCHI, H. et al. Clima da estação experimental da UFRGS (e região de abrangência). Porto Alegre: UFRGS, 2003. 77 p.

BUDYKO, M. I. Atlas tieplobogo balansa zemnogo shara. Atlas do balanço calórico do globo terrestre. Moscou: [s. n.], 1963. 69 mapas.

BURGOS, J. J. El clima de la Provincia de Buenos Aires en relación con la vegetación natural y el suelo. In: CABRERA, A. L. Flora de la Província de Buenos Aires. Buenos Aires: INTA, 1969. p. 33-39.

BURGOS, J. J. El clima de la Región Noreste de la Republica Argentina con la vegetación natural y el suelo. Boletín de la Sociedad Argentina de Botânica, Buenos Aires, v. 11, p. 37-102, 1970.

BURIOL, G. A. et al. Clima e vegetação natural do estado do Rio Grande do Sul segundo o diagrama climático de Walter e Lieth. Ciência Florestal, Santa Maria, v. 17, n. 2, p. 91-100, 2007.

CAMARGO, P. Classificação climática para zoneamento de aptidão agroclimática. In: CONGRESSO BRASILEIRO DE AGROMETEOROLOGIA, 7., 1991, Viçosa, MG. Resumos... Viçosa, MG: Sociedade Brasileira de Agrometeorologia; Universidade Federal de Viçosa, 1991. p. 126-131.

GAUSSEN, H. L'indice xérothermique. Bulletin de l'Association de Géographes Français, Paris, p. $10-16,1954$.

HOLDRIDGE, L. R. Ecologia basada en zonas de vida. San José: IICA, 1978. 216 p. 
INSTITUTO DE PESQUISAS AGRONÔMICAS. Atlas agroclimático do estado do Rio Grande do Sul. Porto Alegre: Secretaria da Agricultura e Abastecimento, 1989. v. 1.

KLEIN, R. M. Southerm braziliam phytogeografhic features and the probable influence of upper quaternary climatic changes in the floristic distribution. Boletim Paranaense de Geociências, Curitiba, n. 33, p. 67-88, 1975.

KOEPPEN, W. Grundriss der Klimakunde. Berlin: Walter de Gruyter, 1931. 288 p.

KOEPPEN, W. Climatologia. México: Fundo de Cultura Economica, 1948. 466 p.

KUINCHTNER, A.; BURIOL, G. A. Clima do estado do Rio Grande do Sul segundo a classificação climática de Koeppen e Thornthwaite. Disciplinarum Scientia, Santa Maria, v. 2, n. 1, p. 171-182, 2001.

LANG, R. Versuch eiver exakten Klassifikation der böden in Klimatischer und geologischer Hinsicht. International Mitt. für Bdenkunde, Stuttgart, n. 8, v. 7, p. 312-346, 1915.

LAUER, W. Von Humide und aride Jahreszeiten in Afrika und Südamerica und ihre Beziehung zu den Vegetationsgürteln. Bonner geographische Abhanalungen, Hyft, v. 9, p. 83, 1952.

LEITE, P. F.; KLEIN, R. M. Vegetação. In: GEOGRAFIA do Brasil: Região Sul. Rio de Janeiro: Instituto de Geografia e Estatística, 1990. v 2. p. 113-150.

MAACK, R. Notas preliminares sobre o clima, solo e vegetação no Estado do Paraná. Arquivo Biológico Técnico, Curitiba, v. 3, p. 103-200, 1948.

MARCHIORI, J. N. C. Fitogeografia do Rio Grande do Sul: campos sulinos. Porto Alegre: Edições EST, 2004. 110 p.

MARCHIORI, J. N. C. Fitogeografia do Rio Grande do Sul: enfoque histórico e sistemas de classificação. Porto Alegre: Edições EST, 2002. 118 p.

MARTONNE, E. Une nouvelle fonction climatologique: 1'indice d'aridité. La Météorologie, Paris, p. 449-459, oct. 1926.

MILLER, A. A. Climatologia. 3. ed. Barcelona: Ediciones Omega, 1966. 379 p.

MONEY, D. C. Climate, soils and vegetation. London: University Tutorial Press, 1974. 272 p.

ODUM, E. P. Ecologia. Rio de Janeiro: Guanabara, 1988. 434 p.

RAMBO, B. A fisionomia do Rio Grande do Sul: ensaio de monografia natural. Porto Alegre: Livraria Selbach, 1956. 456 p.

TCHEBAKOVA, N. M. et al. A global vegetation model based on the climatological approach of Budyko. Journal of Biogeography, oxford, n. 28, p. 129-144, 1993.

THORNTHWAITE, C. W. The climates of North according to a new classification. The Geographical Review, p. 633-655, oct. 1931.

THORNTHWAITE, C. W. An approach towards a rational classification of climate. Geographycal Review, London, v. 38, n. 1, p. 55-94, 1948.

THORNTHWAITE, C. W.; HARE, F. K. Climate classification in forestry. Unasylva, Roma, v. 9, n. 2, 1955.

THORNTHWAITE, C. W.; MATHER, J. R. Water balance. Climatology, New Jersey, v. 8, n. 1, p. 1-104, 1955.

VELOSO, H. P. Os grandes climas do Brasil. Considerações sobre a vegetação na Região Sul-brasileira. Memórias do Instituto Oswaldo Cruz, Rio de Janeiro, v. 60, n. 2, p. 175-194, 1962.

WALTER, H. Vegetação e zonas climáticas. São Paulo: Editora Pedagógica e Universitária, 1986. 325 p.

WALTER, H.; LIETH, H. Klimadiagramm-Waltatlas. Jena: Gustav Fischer, 1960.

WHITTAKER, R. H. Communities and ecosystems, 2nd ed. New York: Macmillan, 1975.

YANLING, S.; XIAODONG, Y.; DETI, X. A new method of vegetation - climate classification in China. International Journal of Climatology, Londres, v. 28, p. 1163-1173, 2008. 